\title{
Fire Dynamics Simulation and Evacuation for a Large Shopping Center (Mall), Part II, Evacuation Scenarios
}

\author{
Khalid A. Albis", Ahmed F. Abdel Gawad, Muhammad N. Radhwi \\ Mechanical Engineering Department, College of Engineering \& Islamic Architecture, Umm Al-Qura University, Makkah, Saudi Arabia
}

Email address:

kalbis31@gmail.com (K. A. Albis), afaroukg@yahoo.com (A. F. A. Gawad),mnradhwi@uqu.edu.sa (M. N. Radhwi)

To cite this article:

Khalid A. Albis, Ahmed F. Abdel Gawad, Muhammad N. Radhwi. Fire Dynamics Simulation and Evacuation for a Large Shopping Center (Mall), Part II, Evacuation Scenarios. American Journal of Energy Engineering. Special Issue: Fire, Energy and Thermal Real-life Challenges. Vol. 3, No. 4-1, 2015, pp. 72-78. doi: 10.11648/j.ajee.s.2015030401.15

\begin{abstract}
Evacuation plans in large malls are very essential in cases of emergency especially fire. Many fatalities may occur among panicked people running and pushing to get out of these burning places. The present study considers evacuation cases corresponding to the fire cases that were considered in part I. It is established that evacuation planning is vital to help people get out of the mall without being exposed to suffocation due to smoke inhaling or having accidents due to panic rush in corridors and over the stairs/escalators.
\end{abstract}

Keywords: Fire Dynamics Simulation, Smoke Propagation, Evacuation, Shopping Center (Mall)

\section{Literature Review}

A simplified elevator service model was developed to evaluate effectiveness of evacuation by elevators and conducted some case studies to examine the feasibility and problems of elevator use for evacuation of aged people in Japan. It was found that the diverging point of the advantage of evacuation by elevator in comparison to evacuation by stairs appears roughly on the $14^{\text {th }}$ floor to the $16^{\text {th }}$ floor [1]. The factors that affect the evacuation process were considered to foresee the human behavior in case of fire. These factors are related to the occupants' characteristics, the building characteristics and the fire characteristics. It was concluded that keen consideration should be given to the interplay of these factors to gain a better understanding of human behavior in fire and to improve the design and implementation of fire safety systems in buildings [2].

An analysis of staff behavior in five unannounced evacuations of Marks and Spencer retail stores was carried out. The retail stores participating in the study comprised two three-story city-center stores and one single-story out-oftown store in different locations in the United Kingdom. It was found that staff responses to the alarm, both in terms of time and nature of their responses, varied depending on the setting they were in and their associated responsibilities. Contrary to their training, they did not always respond immediately by evacuating customers but, in the majority of cases, first sought confirmation of the need to evacuate. They did, however, have a significant impact on customer response, not only in overcoming customers' initial evacuation inertia but also in directing them towards suitable exits [3]. EXODUS software was used to study the emergency evacuation in supermarkets. Thus, many actual factors were considered such as the number of customers, the ratio of personnel's age, the walking speed. The safety measures of supermarket management for evacuation were proposed [4].

The definition of "panic" was reviewed based on actual fire incidents that may have been misreported or misinterpreted as "panic". It was stated that despite the numerous evidence that panic is a very rare occurrence in fires, the idea of panic and the term continue to be used by the public as well as fire experts. Thus, it is necessary to demystify the misconception that panic is an essential element of a fire and identify any scientific justification for continuing using this concept [5]. A comprehensive review was carried out to provide guidance to engineers involved in the design of underground transportation systems for evacuation planning in case of fire. The review revealed many potential solutions to commonly observed evacuation problems [6]. Code $F D S+E v a c$ was used for $3 D$ simulations of fire dynamics and evacuation for a building of 20 floors in China with an area of $2060 \mathrm{~m}^{2}$ (Technological Department of Wuhan University of Technology). The purpose of the work was to improve the speed of occupants' evacuation [7]. Recently, other evacuation studies were addressed [8-12]. 


\section{Evacuation Cases}

Based on the results of the four fire cases, part I, four evacuation cases were studied. The four evacuation cases suggest the scenarios of people evacuation in the four cases of fire. To consider the differences of the evacuated persons (gender, age, etc.), their moving speed was set between 2.1 and $2.5 \mathrm{~m} / \mathrm{s}$. As will be seen in all cases, it is obvious that the flow of persons was faster than the smoke movement. Hence, all persons left the floor safely through the emergency exit and the smoke did not reach anyone of them. Thus, the evacuation process was successful.

\subsection{Case Study (1)}

The first case study concerned evacuation in case of fire ignition at kitchen (7) of the food court in the upper floor, Fig. 1. The evacuation process is based on one hundred persons that are located in the area of the food court.

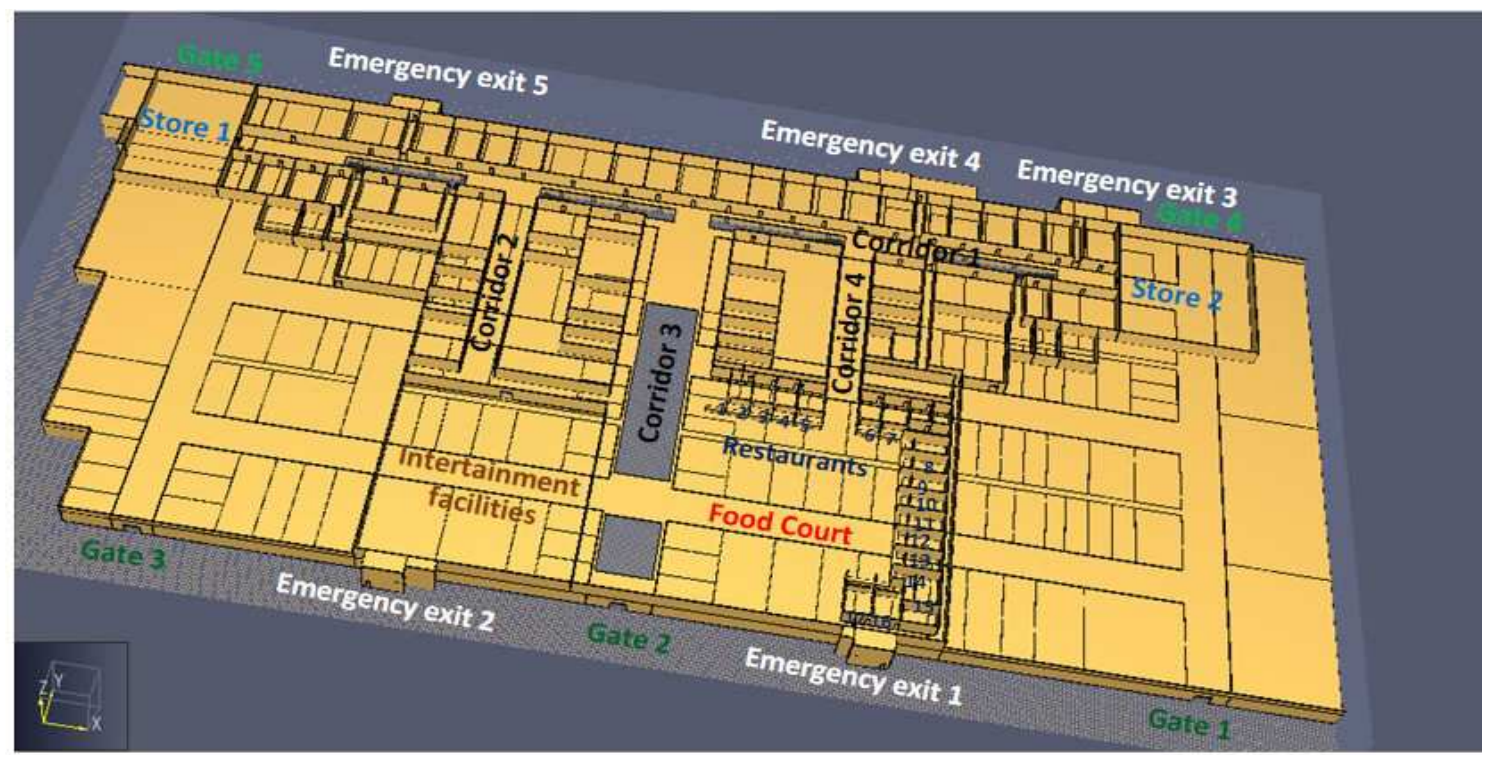

Figure 1. Main stores, corridors, and emergency exits in the upper floor.

The evacuation process and the persons' movement with time are demonstrated in Fig. 2. The persons' movement with time can be monitored from Fig. 2 as follows:

1- After 5 seconds of fire start, persons started to move in the area of the food court, Fig. 2(a).

2- After 10 seconds, persons in the food court area moved to exit (5) through corridor (3), Fig. 2(b).

3- After 20 seconds, three-fourths (3/4) of persons moved from the food court area to corridor (3), Fig. 2(c).

4- After 40 seconds, most persons moved through corridor (1) that leads to exit (5). Some others entered a store in corridor (3) through one entrance and exited from another entrance in corridor (4) that leads also to exit (5), Fig. 2(d).

5- After 60 seconds, most persons moved in corridor (1) that leads to exit (5). Only eight persons moved in corridor (4), Fig. 2(e).

6- After 70 seconds, the first person entered exit (5), then the rest of persons started to follow him, Fig. 2(f).

7-After 90 seconds, most persons entered the small corridor that leads to exit (5), Fig. 2(g).

8- After 120 seconds, the majority of persons had left exit (5), Fig. 2(h).

9- After 130 seconds, the last person entered exit (5) and left the upper floor, Fig. 2(i).

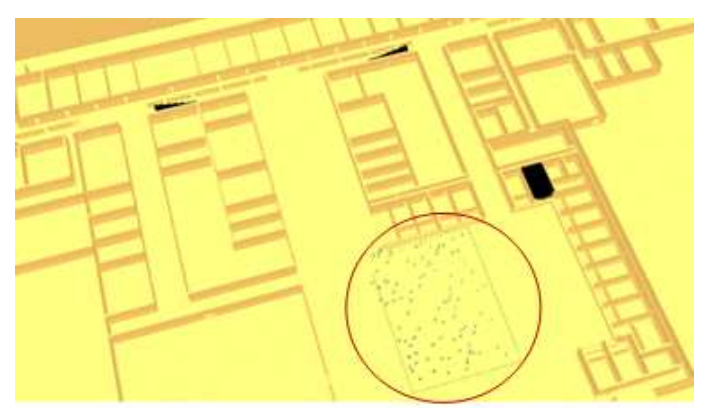

Figure 2(a). $5 \mathrm{Sec}$.

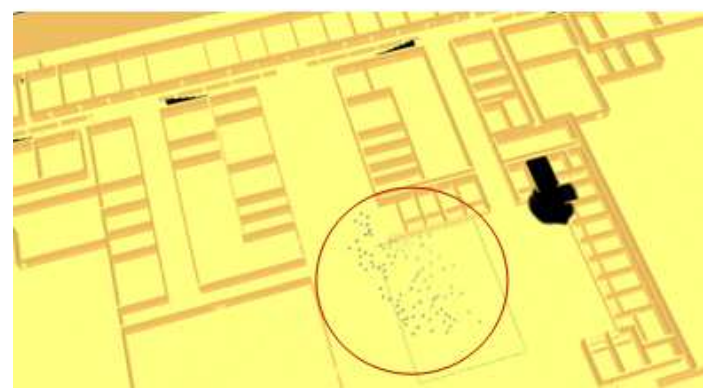

Figure 2(b). $10 \mathrm{Sec}$. 


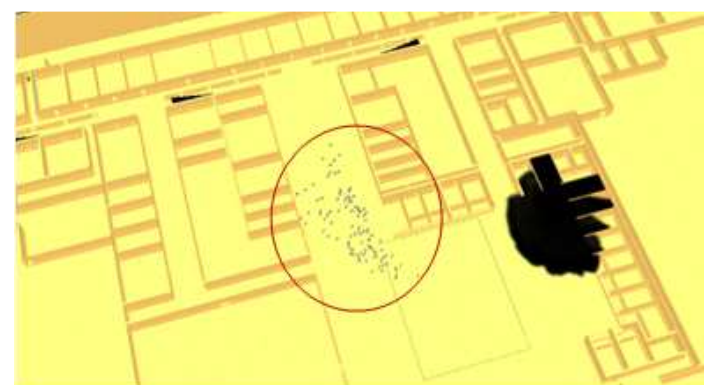

Figure 2(c). $20 \mathrm{Sec}$.

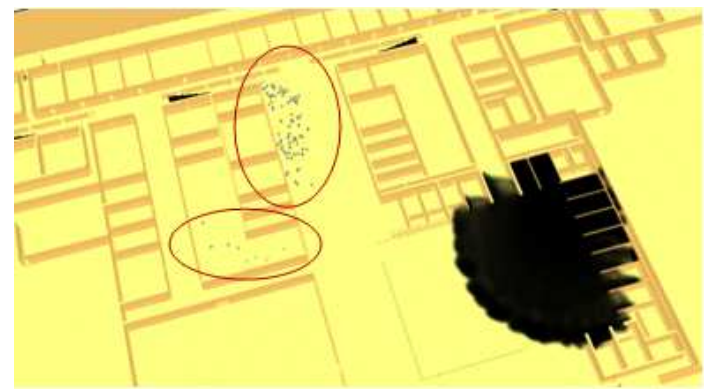

Figure 2(d). $40 \mathrm{Sec}$

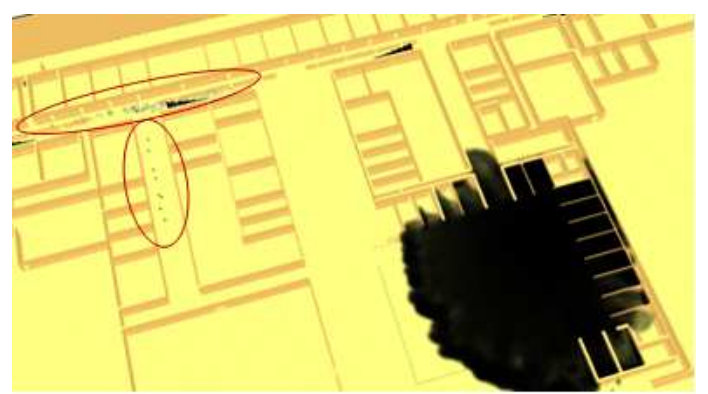

Figure 2(e). $60 \mathrm{Sec}$. (1 Min.).

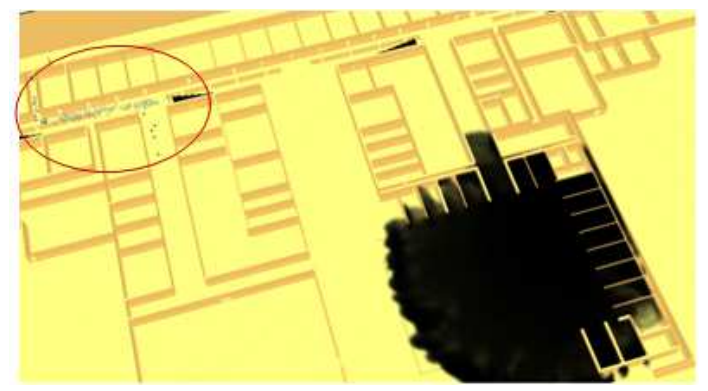

Figure 2(f). $70 \mathrm{Sec}$.

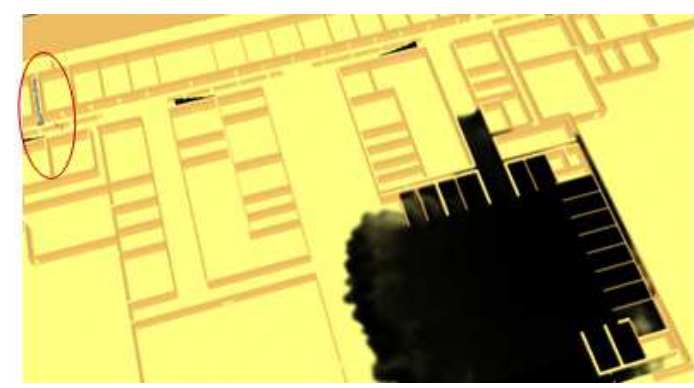

Figure 2(g). $90 \mathrm{Sec}$.

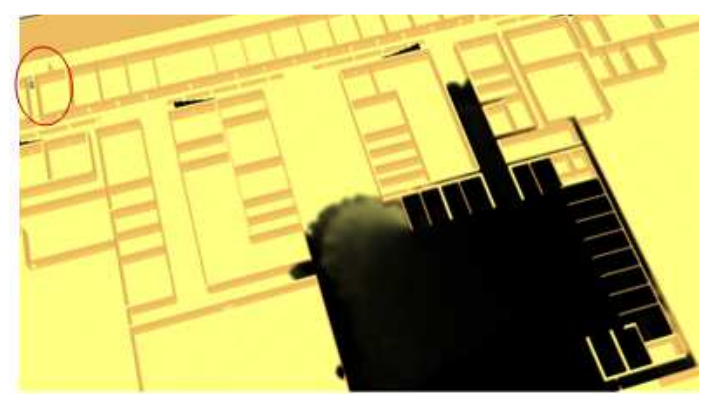

Figure 2(h). 120 Sec. (2 Min.).

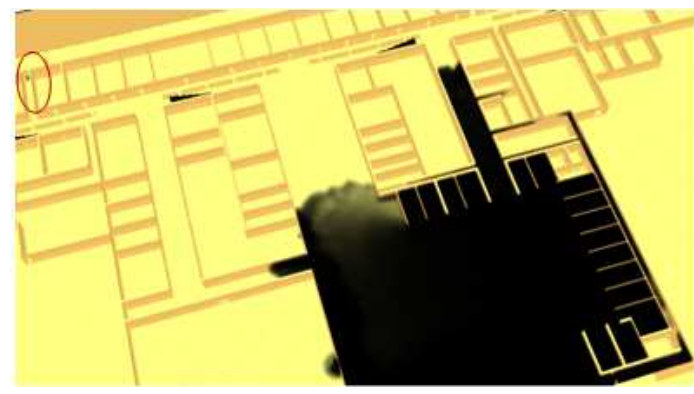

Figure 2(i). $130 \mathrm{Sec}$.

Figure 2. Development of evacuation process with time, Case (1).

\subsection{Case Study (2)}

The second case study concerned evacuation in case of fire ignition at main store (2) in the upper floor, Fig. 1. The evacuation process is based on eighty persons that are located in corridor (1) in front of main store (2).

The evacuation process and the persons' movement with time are demonstrated in Fig. 3. The persons' movement with time can be monitored from Fig. 3 as follows:

1- After 5 seconds of fire start, persons started to move in corridor (1) in front of store (2), Fig. 3(a).

2- After 10 seconds, persons moved on corridor (1) towards emergency exit (4), Fig. 3(b).

3- After 20 seconds, persons approached emergency exit (4), Fig. 3(c).

4- After 30 seconds, almost $50 \%$ of persons moved into the small corridor that leads to emergency exit (4), Fig. 3(d).

5- After 40 seconds, the majority of persons entered in the small corridor that leads to emergency exit (4), Fig. 3(e).

6- After 50 seconds, most persons escaped through emergency exit (4), Fig. 3(f).

7- After 60 seconds, the last person escaped through emergency exit (4), Fig. 3(g).

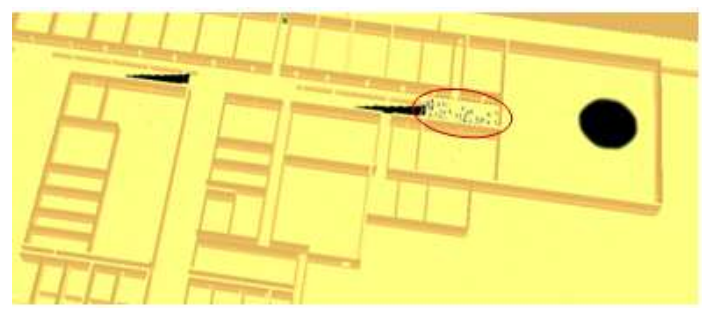

Figure 3(a). $5 \mathrm{Sec}$. 


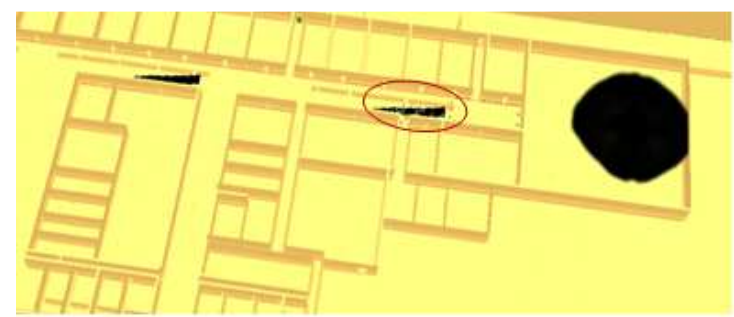

Figure 3(b). $10 \mathrm{Sec}$.

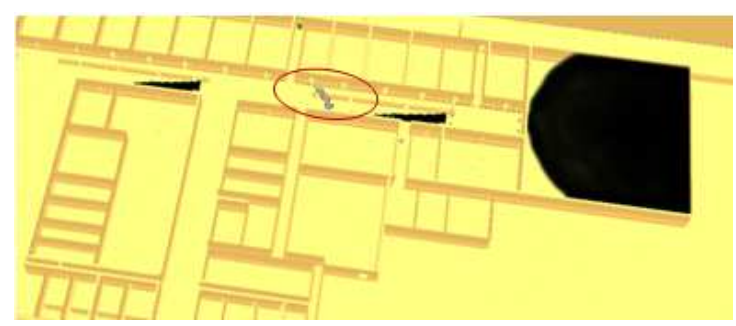

Figure 3(c). 20 Sec.

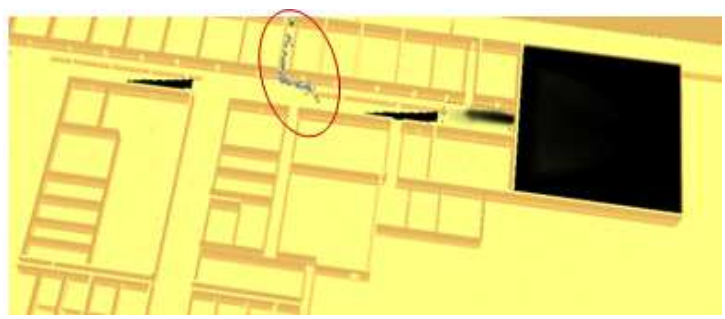

Figure 3(d). $30 \mathrm{Sec}$.

\subsection{Case Study (3)}

The third case study concerned evacuation in case of fire ignition at main store (3) in the ground floor, Fig. 4. The evacuation process is based on one hundred persons that are located in the main store (3).

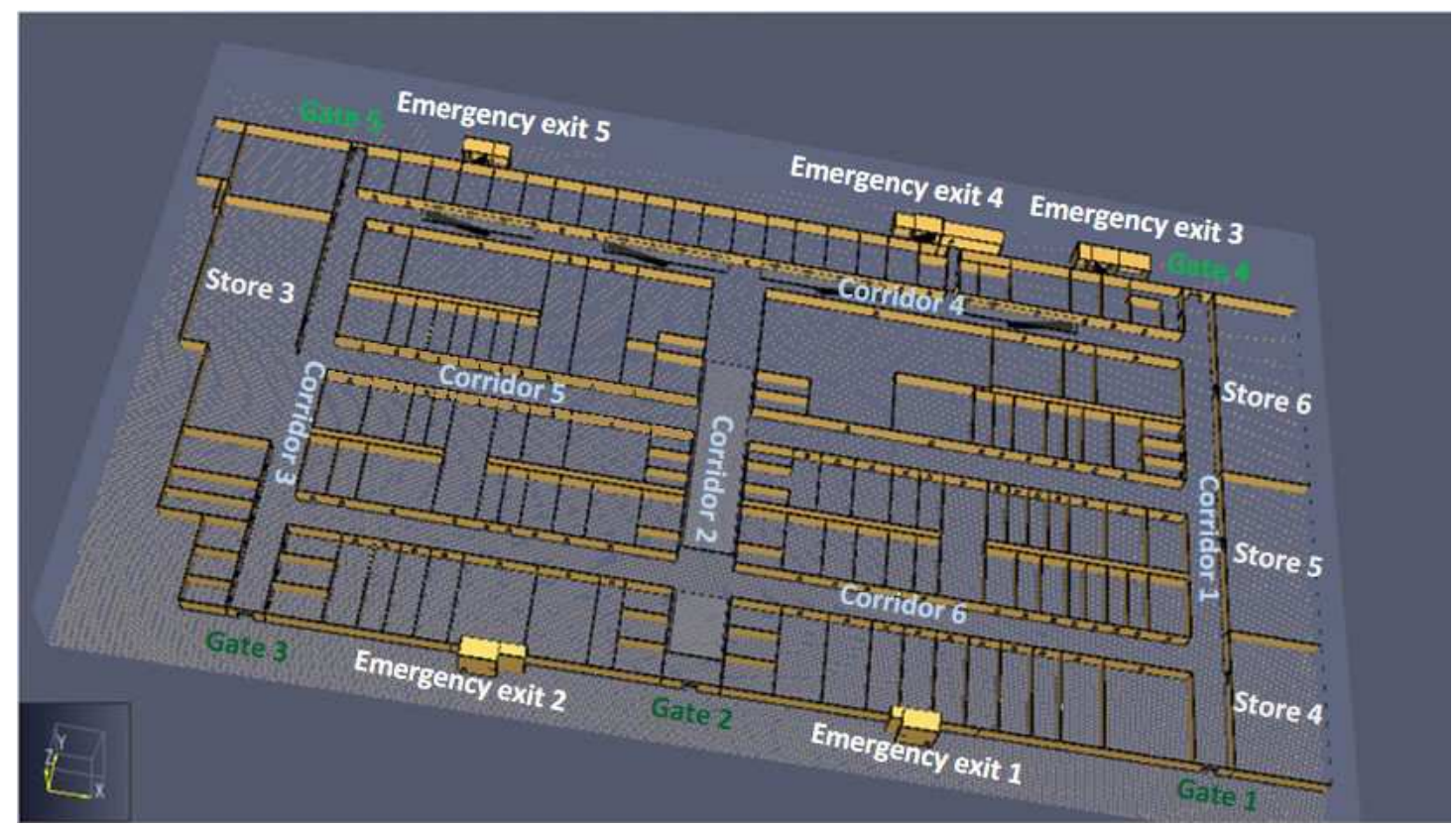

Figure 4. Main stores, corridors, and emergency exits in the ground floor.
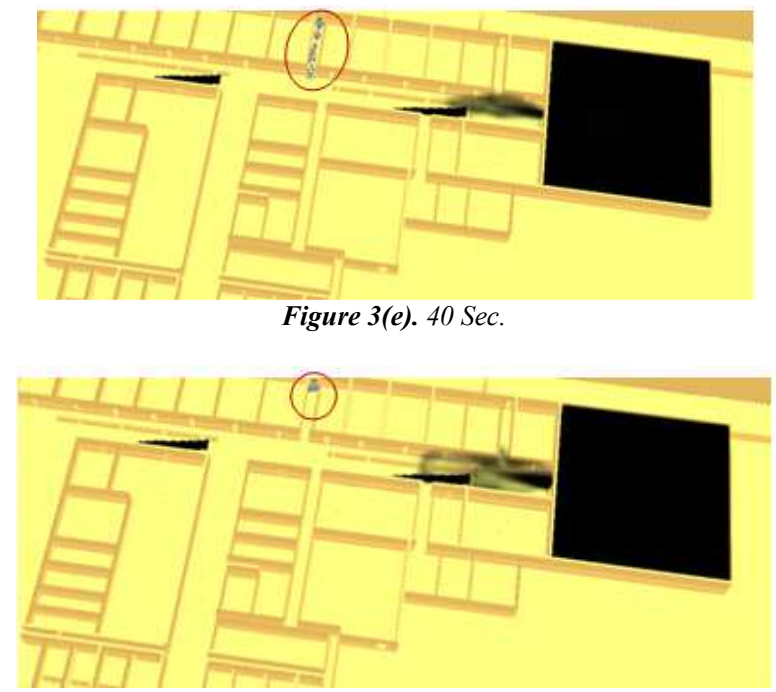

Figure 3(f). $50 \mathrm{Sec}$.

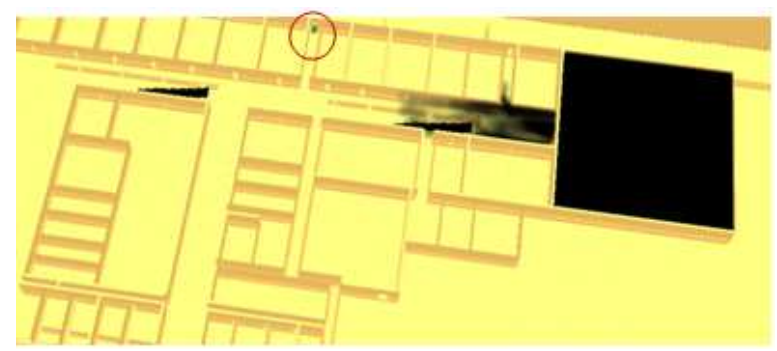

Figure 3(g). $60 \mathrm{Sec}$. (1 Min.).

Figure 3. Development of evacuation process with time, Case (2). 
The evacuation process and the persons' movement with time are demonstrated in Fig. 5. The persons' movement with time can be monitored from Fig. 5 as follows:

1- After 5 seconds of fire start, persons started to move in store (3), Fig. 5(a).

2- After 10 seconds, most persons moved to corridor (3) on their way to main gate (3), Fig. 5(b).

3- After 20 seconds, all persons moved to corridor (3) and the first person exited main gate (3), Fig. 5(c).

4- After 30 seconds, many persons exited from main gate (3), Fig. 5(d).

5- After 40 seconds, the last person exited from main gate (3), Fig. 5(e).

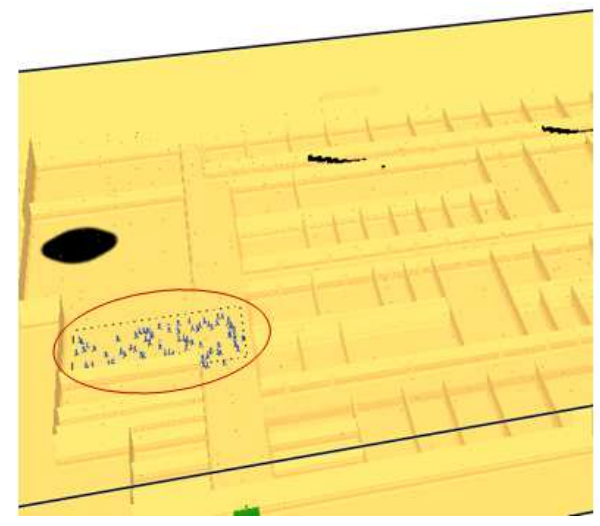

Figure 5(a). $5 \mathrm{Sec}$.

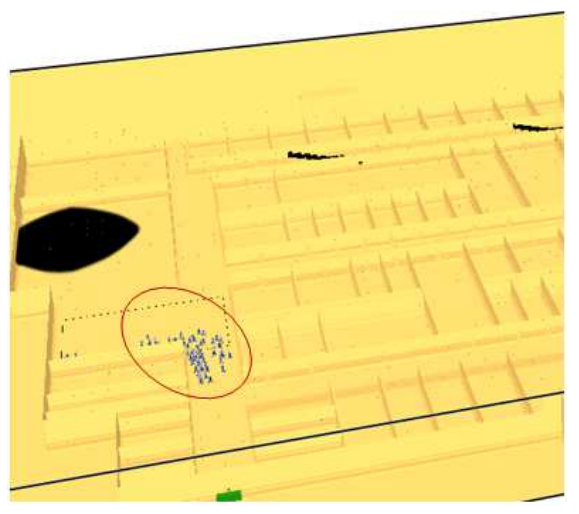

Figure 5(b). $10 \mathrm{Sec}$.

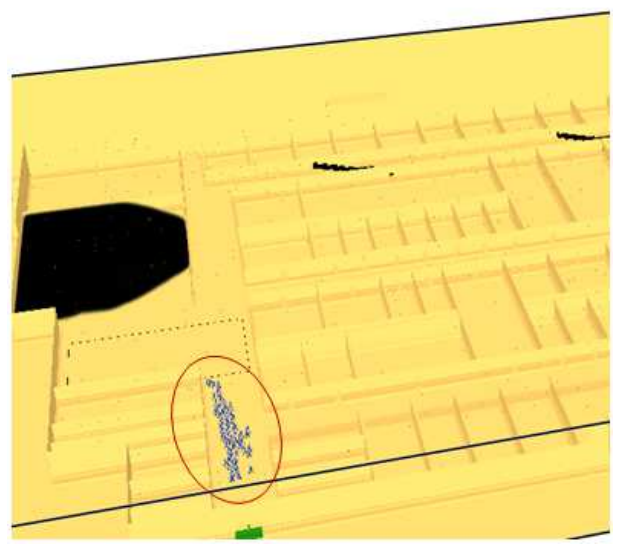

Figure 5(c). $20 \mathrm{Sec}$.

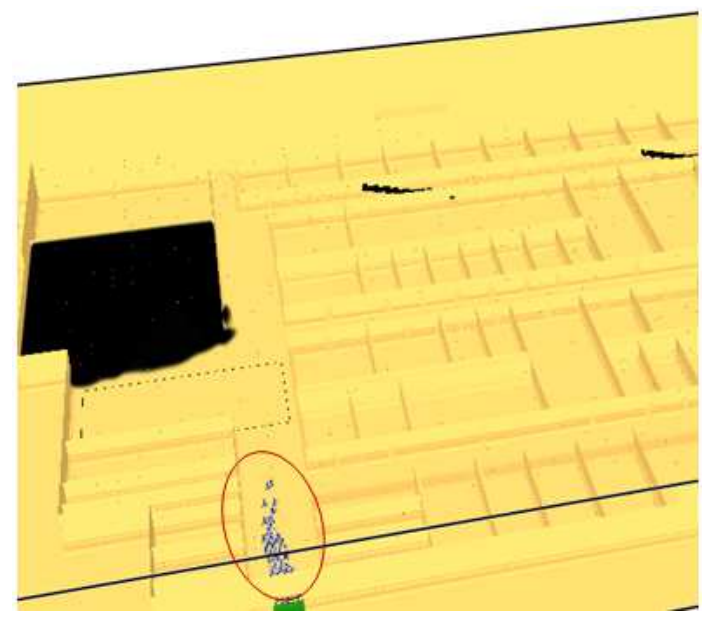

Figure 5(d). $30 \mathrm{Sec}$

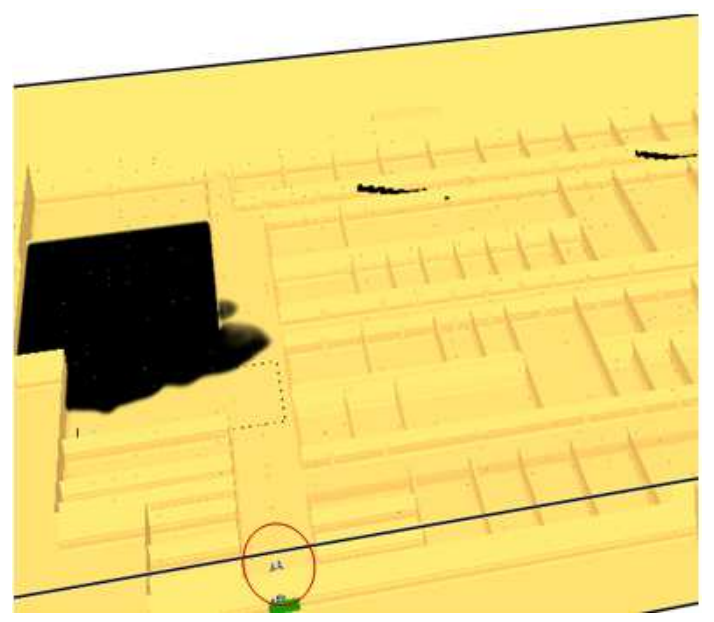

Figure 5(e). $40 \mathrm{Sec}$.

Figure 5. Development of evacuation process with time, Case (3).

\subsection{Case Study (4)}

The fourth case study concerned evacuation in case of fire ignition at main store (5) in the ground floor, Fig. 4. The evacuation process is based on one hundred persons that are located in corridor (1) in front of main store (5).

The evacuation process and the persons' movement with time are demonstrated in Fig. 6. The persons' movement with time can be monitored from Fig. 6 as follows:

1- After 5 seconds of fire start, persons started to move in corridor (1) in front of store 5, Fig. 6(a).

2- After 10 seconds, persons moved in corridor (1) towards main gate (1), Fig. 6(b).

3- After 20 seconds, persons approached main gate (1), Fig. 6(c).

4- After 30 seconds, persons started to get out the mall through main gate (1), Fig. 6(d).

5- After 40 seconds, all persons had left the mall through main gate (1), Fig. 6(e). 


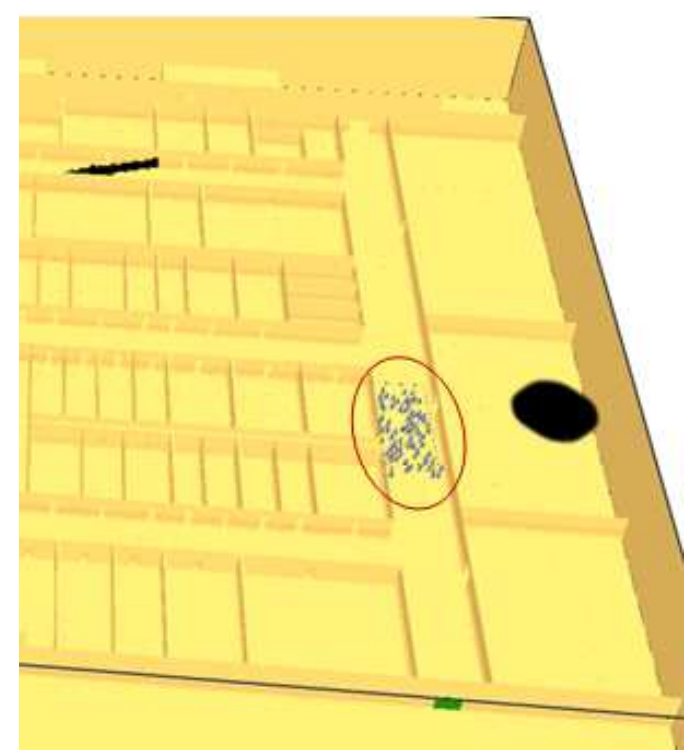

Figure 6(a). $5 \mathrm{Sec}$.

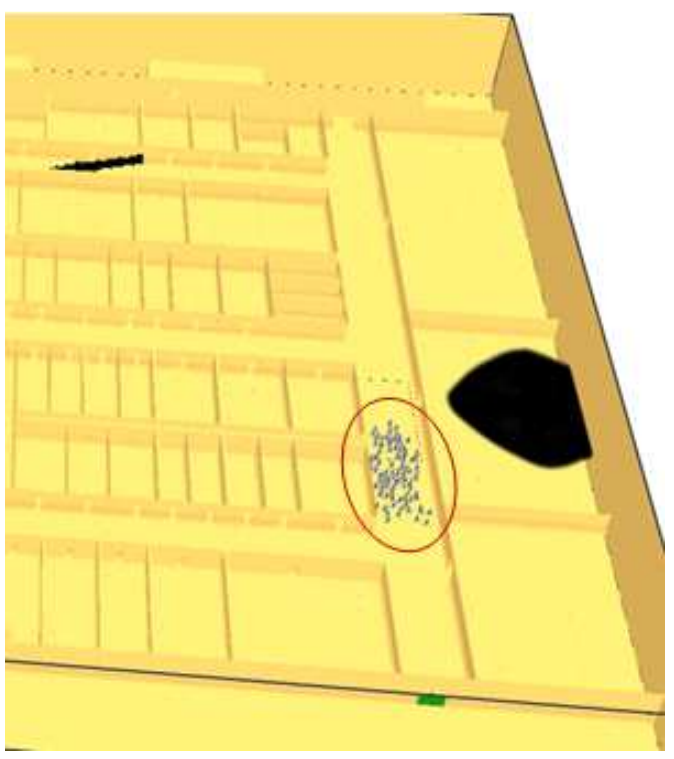

Figure 6(b). $10 \mathrm{Sec}$.

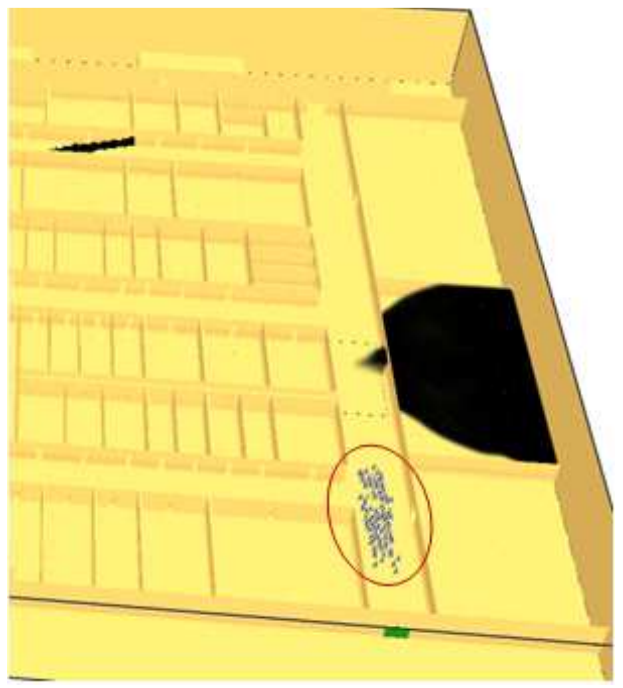

Figure 6(c). $20 \mathrm{Sec}$.

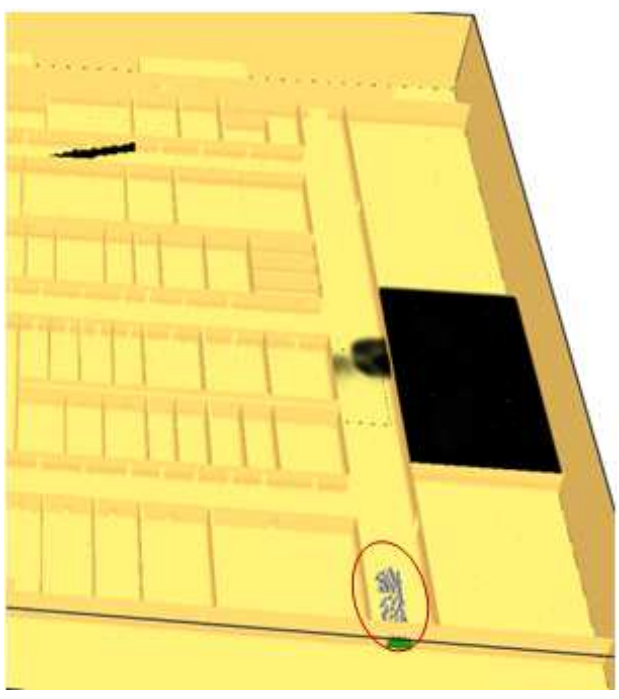

Figure 6(d). $30 \mathrm{Sec}$.

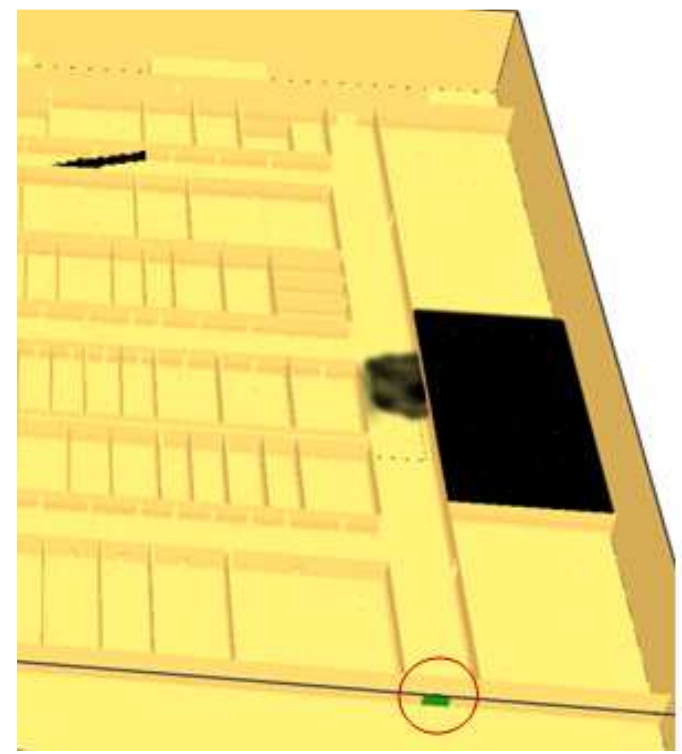

Figure 6(e). $40 \mathrm{Sec}$.

Figure 6. Development of evacuation process with time, Case (4).

\section{Conclusions}

The present investigation concerns smoke propagation and evacuation due to fires in a large shopping center (mall) in Makkah, Saudi Arabia. The mall is a two-story building. Four evacuation cases were considered. Half of the cases were implemented for the ground floor and the other half were implemented for the upper floor.

Based on the present results, the following concluding points can be stated:

1 - It is well-established that evacuation planning is vital to help people get out of the mall without being exposed to suffocation due to smoke inhaling or having accidents due to panic rush in corridors and over the stairs/escalators.

2- For all the present four cases of evacuation, all persons left the corresponding floor safely through the nearest 
emergency exit and the smoke did not reach anyone of them. Thus, the evacuation processes were totally successful.

3 - For the present cases, it was found that 60 seconds were enough to evacuate all persons from the upper floor. However, 40 seconds were enough to evacuate all persons from the ground floor.

4- It is clear that the assigned velocity range of persons during evacuation $(2.1$ and $2.5 \mathrm{~m} / \mathrm{s})$ was suitable for the four evacuation cases considering the differences of persons (gender, age, etc.).

\section{Nomenclature}

$\begin{array}{ll}3 \mathrm{D} & : \text { Three-dimensional } \\ \text { Evac } & : \text { Evacuation software } \\ \text { EXODUS } & : \text { Evacuation software } \\ \text { FDS } & : \text { Fire Dynamics Simulator }\end{array}$

\section{References}

[1] A. Sekizawa, S. Nakahama, Y. Ikehata, M. Ebihara, and H. Notake, "Study on Feasibility of Evacuation by Elevators in a High-Rise Building-A Case Study for the Evacuation in the Hiroshima Motornachi High-Rise Apartments", AOFST 4, International Association for Fire Safety Science, pp. 217-225, 2000 .

[2] G. Proulx, "Occupant Behaviour and Evacuation", 9th International Fire Protection Symposium, Munich, 25-26 May 2001.

[3] D. A. Samochine, K. Boyce, and T. J. Shields, "An Investigation into Staff Behaviour in Unannounced Evacuations of Retail Stores-Implications for Training and Fire Safety Engineering", Fire Safety Science 8, pp. 519-530, 2005. Doi: 10.3801/IAFSS.FSS.8-519.

[4] L. Qiang, and J. Hong-yu, "The Study on Safety Evaluation of
Evacuation in a Large Supermarket", 5th Conference on Performance-based Fire and Fire Protection Engineering, Procedia Engineering, Vol. 11, pp. 273-279, 2011. Doi:10.1016/j.proeng.2011.04.657.

[5] R. F. Fahy, G. Proulx, and L. Aiman, "Panic or not in Fire: Clarifying the Misconception", Fire and Materials, Special Issue on Human Behaviour in Fire, Vol. 36, No. 5-6, pp. 328338, Oct. 2012.

[6] K. Fridolf, D. Nilsson, and H. Frantzich, "Fire Evacuation in Underground Transportation Systems: A Review of Accidents and Empirical Research", Fire Technology, Vol. 49, No. 2, pp. 451-475, April 2013.

[7] A. L. da Silva, "Study of Building Fire Evacuation and Geometric Modeling Based on Continuous Model FDS+AVEC", European Scientific Journal, May 2014, SPECIAL/ edition ISSN: 1857 - 7881 (Print) e - ISSN 18577431.

[8] M. Xi, and S. P. Smith, "Exploring the Reuse of Fire Evacuation Behaviour in Virtual Environments", Proceedings of the $11^{\text {th }}$ Australasian Conference on Interactive Entertainment (IE 2015), Vol. 27, p. 30, 2015.

[9] Y. Chen, Y. Cai, P. Li, and G. Zhang, "Study on Evacuation Evaluation in Subway Fire Based on Pedestrian Simulation Technology", Mathematical Problems in Engineering, Vol. 2015, 2015.

[10] X. Che, Y. Niu, B. Shui, J. Fu, G. Fei, P. Goswami, and Y. Zhang, "A Novel Simulation Framework Based on Information Asymmetry to Evaluate Evacuation Plan", The Visual Computer, May 2015.

[11] J. Kang, I.-J. Jeong, and J.-B. Kwun, "Optimal Facility-Final Exit Assignment Algorithm for Building Complex Evacuation", Computers \& Industrial Engineering, Vol. 85, pp. 169-176, July 2015.

[12] M. T. Kinateder, E. D. Kuligowski, P. A. Reneke, and R. D. Peacock, "Risk Perception in Fire Evacuation Behavior Revisited: Definitions, Related Concepts, and Empirical Evidence", Fire Science Reviews, Vol. 4, No. 1, pp. 1-26, 2015. 